\title{
Decarbonizing the heating supply of an urban district in Kazakhstan
}

\author{
Andrea Bartolini ${ }^{*}$,, Ruslan Mukanov ${ }^{2}$ Gabriele Comodi ${ }^{1}$ and Kairatolla Abishev ${ }^{2}$ \\ ${ }^{1}$ Università Politecnica delle Marche, Via Brecce Bianche 12, Ancona, Italy \\ ${ }^{2}$ Pavlodar State University, Lomov St 64, Pavlodar (Kazakhstan)
}

\begin{abstract}
A major contribution to our society's environmental impact lies in meeting the energy needs of buildings, specifically in areas where the supply of such commodities is based on high carbon-emitting fossil fuels (oil/coal). This study analyses a mixed-use urban district situated in Kazakhstan. The district features a set of households together with three schools, a hospital, and several office buildings. The heating energy needs of the city are currently entirely met by coal-fired solutions; thus, this study wishes to investigate the feasibility of novel more sustainable technological approaches. A set of scenarios is modeled by means of the EnergyPLAN analysis tool where the technical feasibility of a district heating network is analyzed in combination with both greener fossil fired solutions and renewables.
\end{abstract}

\section{Introduction}

The path to decarbonization, which is a mandatory objective for our society [1], can have diverse approaches with regard to the energy supply of our communities. In particular, these pathways can leverage local conditions in order to achieve the best results in terms of a set of KPIs: from stimulating local economies to reducing environmental footprints of different kinds $[2,3]$.

A comprehensive evaluation of the effectiveness of a decarbonization solution can be done with an energy planning approach [4]. This paper analyses potential pathways to decarbonize the heat supply of a small community located in Kazakhstan by means of a set of interventions on the systems that meet its energy needs. The primary energy supply of Kazakhstan is almost entirely met through fossil fuels [5]: coal, oil, and natural gas, even if renewables are gaining momentum with different projects thanks to the country's vast potential in terms of solar resource [6,7] and biomass [7]. As a matter of fact, the feasibility of the transition of Kazakhstan's heat and electricity supply towards a $100 \%$ RES-based energy supply system has been already investigated on a country level [8].

But, with regards to the integration of large amounts of RES several authors highlighted the key role that increasingly distributed energy systems will play, particularly if different energy sectors are considered at the same time with a holistic approach, towards distributed multi-energy systems $[3,9,10]$.

The study investigates a residential community located in north-eastern Kazakhstan, near the city of Pavlodar, which meets all of its energy needs by means of fossilfuels based solutions, both through distributed technologies (eg. Boilers) and using the national grid's electricity. The goal of the study is to investigate the feasibility of an energy supply system entirely based on renewable energy sources towards an energy-wise selfsustaining community, also investigating the potential role of storage technologies towards a $100 \%$ renewable energy system.

The switch towards such an energy supply system could be achieved with different technological solutions; within the present study, the attention is framed on the potential of using a renewable supply of energy in terms of electricity (by means of solar PV) and/or biomass, coupled either with electricity-powered heat production devices such as heat pumps (HP) and/or biomass powered micro-CHP (mCHP) and thermal storage systems (TES). Even considering the very low temperatures characterizing most of Kazakhstan heat pumps are still being considered as a valid asset to reach ambitious decarbonization targets with respect to the continuously growing district heating sector [11], mostly thanks to the cheap and easy installation with the existing building stock and the possibility of integrating large capacities of renewable electricity generation sources such as solar photovoltaic (PV) and wind.

\footnotetext{
* Corresponding author: a.bartolini@univpm.it
} 


\section{Materials and Methods}

This section describes the case study that is analyzed, the software tool used to perform the analyses, and the scenarios that are investigated.

\subsection{Leninsky community description}

The case study under analysis is the Leninsky village, located at 52.25, 76.74, in north-eastern Kazakhstan. The village is a small rural community of 10.3 thousand inhabitants over a total surface of approximately 7600 hectares, for a total of 2365 households. The building stock of the area mostly consists of residential households, small commercial activities, three schools, a hospital, and a building destined for cultural activities. An aerial view of the site is shown in Figure 1.

The main energy commodities required by the community are electricity and heat for space heating, given the location no space cooling is needed throughout the year. In particular, the request for space heating is prominent, given the yearly temperatures that average $2.7^{\circ} \mathrm{C}$ over the year, and minimum temperatures that often get as low as $-20^{\circ} \mathrm{C}$. A simulated yearly (obtained from the Renewable Ninja model [12]) temperature curve is shown in Figure 2.

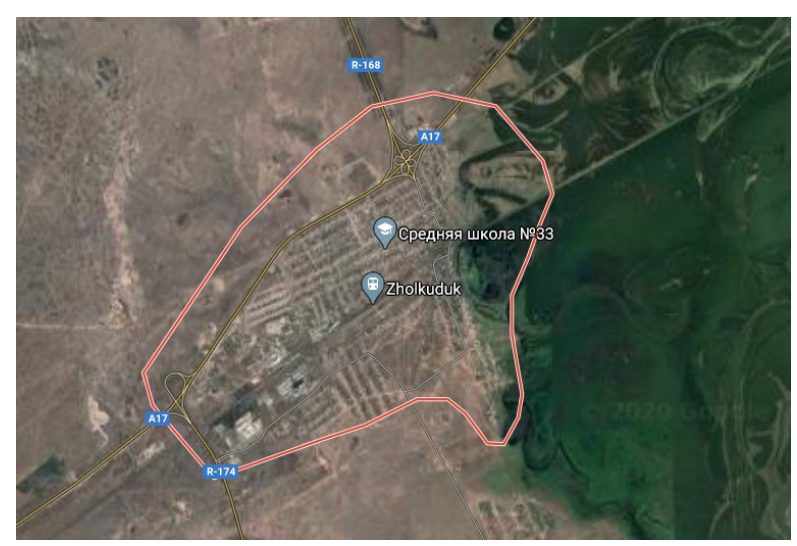

Figure 1 - Aerial view of the Leninsky village

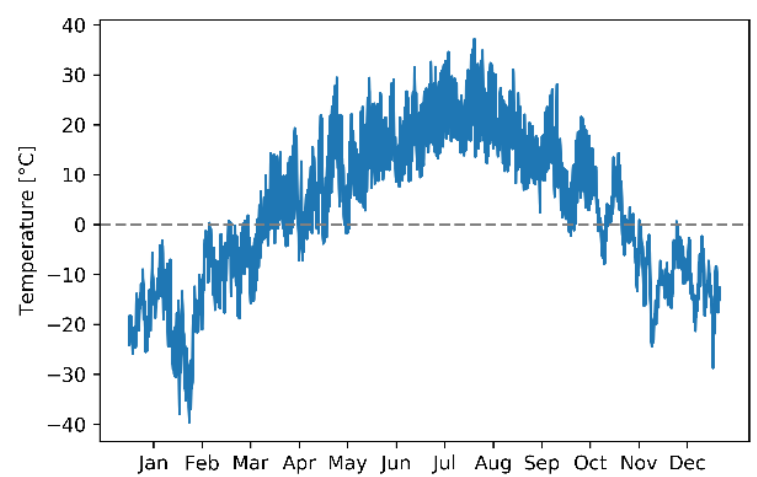

Figure 2 - Yearly temperature for the Leninsky district site.
The district is connected to an electricity distribution infrastructure that can entirely supply the electricity needs of the community; heating on the other hand is entirely supplied by local solutions based on coal boilers, with the coal being transported periodically to the community site.

The available data consists of the yearly total energy demands requested by the community, distinguished by the demands of the households and the rest of the buildings. Furthermore, also the data regarding the supply costs for such energy commodities are provided in KZT, which is converted to USD for convenience using an exchange rate of $1 \mathrm{USD}=430 \mathrm{KZT}$. The data regarding the energy demand is shown in Table 1, while the supply costs are shown in Table 2 , which shows that the energy demands of the community are predominantly residential.

\section{Commodity}

Average demand

Single household coal demand 13.5 ton/year

Single household coal cost $38.8 \$ /$ ton

Single house electricity demand $\quad 4.8 \mathrm{MWh} /$ year

Buildings coal demand 3000 ton/year Buildings coal cost $25.8 \$ /$ ton

Buildings electricity demand $192 \mathrm{MWh} /$ year Electricity cost (both) $0.023 \$ / \mathrm{kWh}$

Table 1 - Building stock yearly energy demands

\begin{tabular}{|lc|}
\multicolumn{1}{c}{ Commodity } & Supply cost \\
Single household coal cost & $38.8 \$ /$ ton \\
Buildings coal cost & $25.8 \$ /$ ton \\
\hline Electricity cost (both) & $0.023 \$ / \mathrm{kWh}$
\end{tabular}

Table 2 - Energy supply costs for coal and electricity. The coal cost includes transport to the village

Overall, the whole community has then an approximate yearly demand of 35,000 tons of coal and 11,500 MWh of electricity.

From such data is already possible to have an estimate on the $\mathrm{CO}_{2}$ emissions generated in meeting the energy demands of the community. As of 2016, the emissions generated in the power sector amounted to 0.98 tonCO $\mathrm{CO}_{2} / \mathrm{MWh}$ of electricity, by considering the transmission and distribution losses (amounting to $7 \%$ [13]) and multiplying by the yearly electricity consumption returns a total of $11.3 \mathrm{kt}$ of $\mathrm{CO}_{2}$ emitted per year. To meet the heating demand a total of 34,927 tons of coal is needed per year, which generates $\mathrm{CO} 2$ emissions for approximately $73.5 \mathrm{kt}$. The total $\mathrm{CO} 2$ emissions then amount to 85.6 yearly $\mathrm{kt}$ but are predominantly originated in meeting the heat demand: for more than $85 \%$ of the total quantity. It's then clear that any intervention aimed at lowering the carbon footprint of the community will have to consider alternative ways to meet the heating demand. 


\subsection{Modeling the community in EnergyPLAN}

To be able to model a potentially complex set of energy conversion and storage technologies, which interact across different energy carriers, the model EnergyPLAN is chosen [14]. The model allows simulating the operation of complex energy systems by meeting the needs of multiple technologies and energy carriers considered, by also modeling a relevant presence of non-controllable renewable energy conversion systems. This is used to model an energy supply for the community predominantly based on solar resources by means of PV systems.

The hourly energy demands to be used in EnergyPLAN are obtained by referring to the yearly totals available from the data. For the electricity profile, these are estimated by referring to residential and commercial hourly profiles available from literature which are used throughout the whole year [15], the profile that is obtained is shown in Figure 3 and considers only appliances such as lighting and electric plugs.

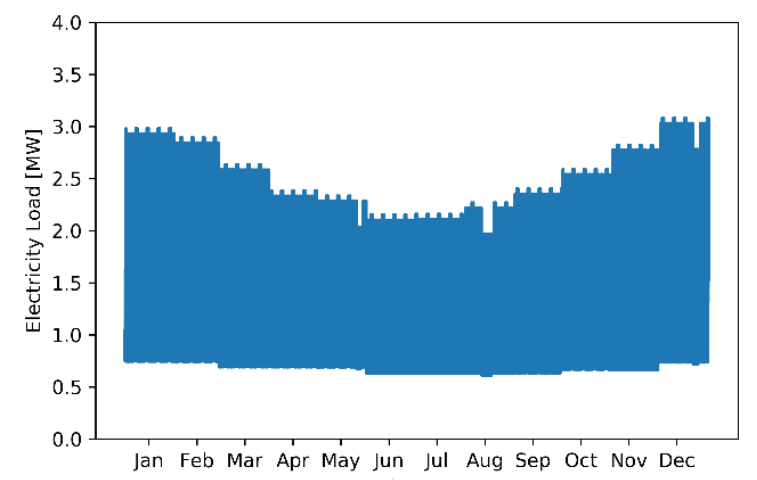

Figure 3 - Hourly profile for the electricity demand

The hourly profile for the heating demand is obtained by referring to the consumption pattern of model buildings which are simulated by means of the EnergyPlus software, using reference building models [16] and setting the location to be the closest available to the Leninsky district, being the city of Pavlodar. The yearly profile that is obtained is shown in Figure 4.

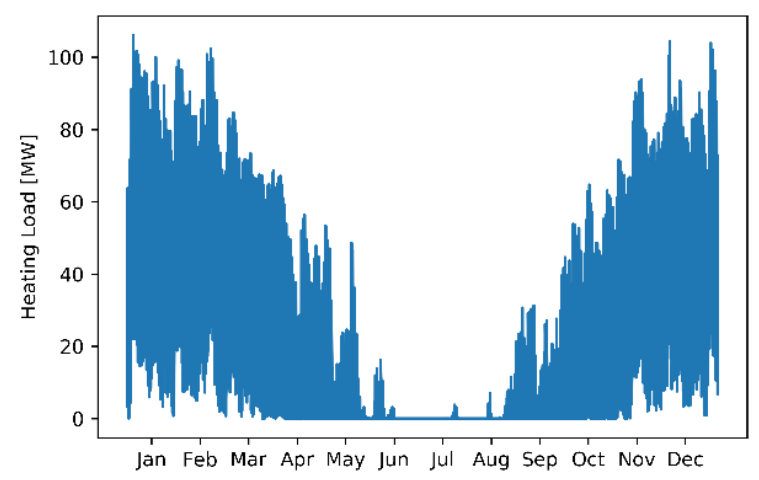

Figure 4 - Yearly profile for the heating demand
The availability of solar resource is modeled by considering data from the Renewable Ninja model [12]: a $1 \mathrm{kWp}$ PV plant is simulated and the yearly timeseries with hourly resolution used as an input to simulate the yield of PV systems deployed in the community. For simplicity, it is assumed that the PV system consists in tilted panels having all the same tilt angle set at $38^{\circ}$ during the whole year (maximizing the yearly capacity factor) and, moreover, not having any sun-tracking capability neither on the azimuth angle. The data that is obtained is shown in Figure 5. Given such reference year, the total amount of electricity that is yielded by a $1 \mathrm{kWp}$ PV system (already accounting for losses) is $1330 \mathrm{kWh}$.

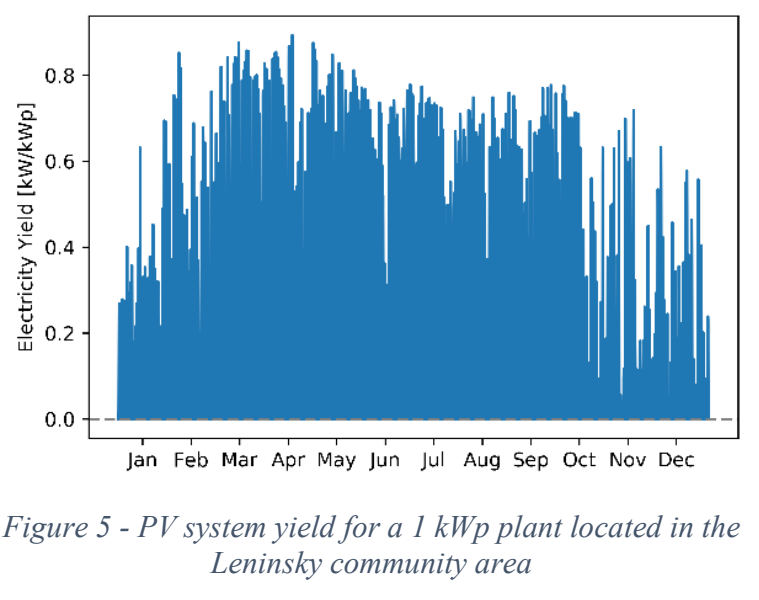

\subsection{System Scenarios \\ parameters \\ \& \\ Investigated}

The scenarios that are proposed investigate the available technological options to decarbonize the energy supply of the community. The RES supply that is investigated is $\mathrm{PV}$, both by means of rooftop systems but also potentially to be placed in the surroundings of the community.

A first scenario (Scenario 1) switches the heating production systems from coal-based boilers to air source heat pumps, still by means of single-household/building individual solutions. With regards to the individual heat pump systems, EnergyPLAN models the heat supplying electric system as a single technology identified by its size and a single conversion efficiency parameter (COP in this case). Such parameter is defined as a single value throughout the whole year in EnergyPLAN and is set to 3 for the electricity to heat conversion following a heat pump performance curve with respect to outside air temperature [17], and considering the yearly average temperature of approximately $3.5^{\circ} \mathrm{C}$ for the location of the Leninsky district obtained averaging the data shown in Figure 2.

By considering the average yearly temperature the COP would surely be overestimated, as heating demand is higher in moments where outside temperatures are lower, thus ultimately leading to lower COPs. But 
nevertheless, in the following scenarios also the possibility of storing heat is considered, which is ultimately the production of heat at moments of high availability of non-controllable electricity. In the case of this paper (considering only PV) the excess electricity would be available only in the central hours of the day, with higher temperatures and therefore COPs. For such reason the representative COP used in EnergyPLAN is left at 3 .

In such scenario the PV system capacity is set to an amount that would grand an electricity production sufficient to meet both the electricity and heating demand. Such electricity amounts to the sum of the community's electricity demand plus the electricity that would be needed to supply the whole heating demand with an electrical heating device with COP equaling 3 , following the same conversion efficiency assumption just described to obtain the size for the PV system.

The first amounts to $11.54 \mathrm{GWh} /$ year and the second amounts to $50.13 \mathrm{GWh} /$ year; for a total of 61.67 GWh/year of electricity. A PV system that meets such demand by considering a $1330 \mathrm{kWh} / \mathrm{kWp}$ would be of approximately $46.4 \mathrm{MWp}$, which is considerably large at $20 \mathrm{kWp}$ per household of the community. This is considered to be a feasible possibility for the setting at hand given the urbanization level and relative isolation of the context where the community being analyzed is located.

The goal of this scenario is to have a quantitative estimate of the unbalance between the electricity produced by the PV systems and the actual electricity and heating demands.

A second scenario (Scenario 2) adds to Scenario 1 the possibility of storing the produced heat for a maximum of 2 days by still using technological solutions at the individual/single-household level. This is investigated in order to understand the potential role of a simple heating storage solution, such as an insulated water tank to increase the RES self-consumption capabilities of the community.

Finally, a third scenario (Scenario 3 ) reduces the amount of PV in the community to a total of $10 \mathrm{MWp}$ (which is closer to systems size which is typical for rooftop installations at approximately $4 \mathrm{kWp}$ per household), and the heating demand is partially switched from a heat pump system to domestic microCHP systems fed by biomass, having a $20 \%$ electric efficiency and a $60 \%$ thermal efficiency. This scenario is intended to study alternative solutions to the sole usage of PV, switching part of the heating demand to biomass and potentially returning a less land footprint demanding design for the energy supply of the district. The share of the heating demand that is left to be met by heat pumps corresponds to the one that should ideally be met by the 10 MWp PV system, which under the hypotheses made produces $13.3 \mathrm{GWh}$ of electricity per year.

Thus, in total, three scenarios are proposed to investigate the decarbonization of the heat supply are listed as follows, and a summary of the settings related to the energy systems in place are shown in Table 3.

1. $\mathrm{PV}+$ individual heat pumps

2. $\mathrm{PV}+$ heat pumps + domestic heat storage
3. $\mathrm{PV}+$ heat pumps/microCHP + domestic heat storage

\begin{tabular}{lccc}
\multicolumn{1}{c}{ Variable } & $\begin{array}{c}\text { Scenario } \\
\mathbf{1}\end{array}$ & $\begin{array}{c}\text { Scenario } \\
\mathbf{2}\end{array}$ & $\begin{array}{c}\text { Scenario } \\
\mathbf{3}\end{array}$ \\
\hline $\begin{array}{l}\text { PV system } \\
\text { size [MWp] }\end{array}$ & 46.4 & 46.4 & 10 \\
$\begin{array}{l}\text { HP heat } \\
\text { demand }\end{array}$ & 150.4 & 150.4 & 39.9 \\
$\begin{array}{l}\text { [GWh] } \\
\text { mCHP heat } \\
\text { demand }\end{array}$ & 0 & 0 & 110.3 \\
$\begin{array}{l}\text { [GWh] } \\
\text { TES [yes/no] }\end{array}$ & No & Yes & yes
\end{tabular}

The simulations aim at comparing the three scenarios with regards to different metrics both among them and with the reference Scenario (the situation as it is now) anticipated in Paragraph 2.1. Such metrics are the environmental impact of the designs, expressed as the amount of $\mathrm{CO} 2$ emissions, and the level of noncontrollable renewable electricity self-consumption that is achievable, which is expressed by the total amount of electricity that must be imported and/or exported. With regards to electricity exports, these are considered as if the electricity could entirely be injected into the grid without curtailments and thus, be used by other users connected to the grid after accounting for transmission and distribution losses. This is considered to reduce the $\mathrm{CO} 2$ emissions of the community as if the surplus electricity would avoid electricity production by the central system.

All the scenarios are confronted with the situation as it is now, named "Reference" from now on in order to have a better grasp of the consequences of the different planning choices.

\section{Results}

The discussion of the results in this section is divided in three sub-sections. The first concerns the electricity import-export imbalance generated by the heavy presence of non-controllable RES, the second the $\mathrm{CO}_{2}$ emissions generated with the novel designs and finally, the third briefly discusses some considerations on the economics of the proposed solutions.

\subsection{Non-controllable electricity imbalance}

The results obtained from the EnergyPLAN simulations are summarized by means of the total yearly electricity imports and exports, shown in Figure 6, and the total yearly $\mathrm{CO} 2$ emissions, shown in Figure 7.

Figure 6 already gives a visual hint at the implications of having large shares of non-controllable electricity in a district: even if the PV system is sized to 
meet the whole demands of electricity and heating there is still a significant lack in synchronization between demand and production causing the need to inject large quantities of electricity into the grid, and consequently forced to withdraw that same amount of electricity during the evening and night. Overall, the community is significantly more reliant on the grid as an asset in order to meet its own energy needs given the need to import and export electricity for approximately $46 \mathrm{GWh}$ per year.

This slightly gets better with the addition of a thermal storage system, as in Scenario 2, where the electricity imports and exports decrease to approximately $34 \mathrm{GWh}$, which is still significantly higher than the $12 \mathrm{GWh}$ of the reference scenario.

Finally, in scenario 3, there is a clear asymmetry between imports and exports: the former is as low as 2 GWh while the latter is still relatively high at $25 \mathrm{GWh}$. This suggests that the availability of making use of electricity by means of PV is intrinsically limited by the energy demand patterns of the case study at hand. On the other hand, the CHP systems allow covering the majority of the electricity needs of the community which can't be met by the PV systems due to a lack of sync.

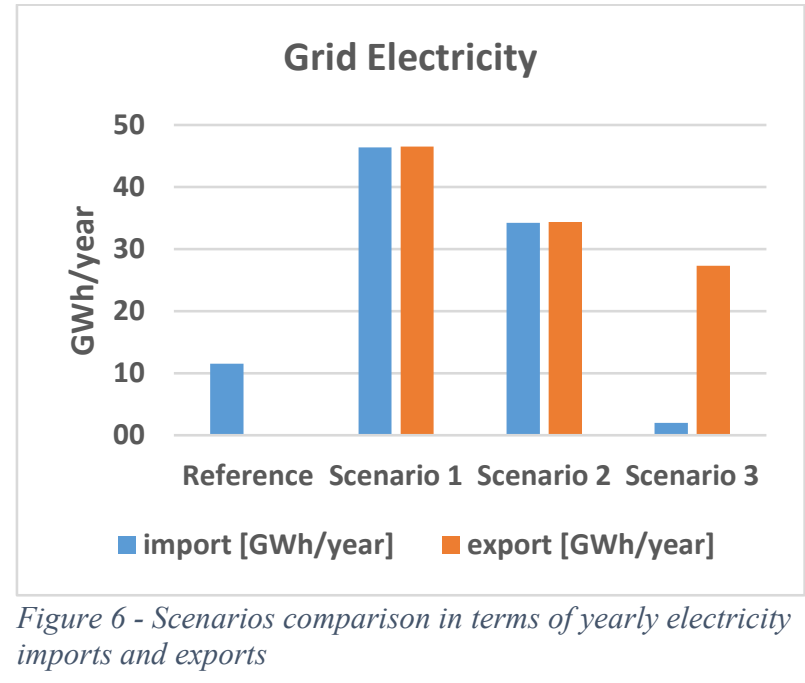

\subsection{Generated emissions}

With regards to emissions, shown in Figure 7, it's clear that all of the proposed scenarios achieve a significant reduction with respect to the reference scenario. From over $85 \mathrm{kt}$ of $\mathrm{CO} 2$ in the reference scenario the emissions lower as much as 6.5 and 4.8 yearly kt of $\mathrm{CO} 2$ in Scenario 2 and Scenario 3 respectively.

In Scenario 3 the $\mathrm{CO} 2$ emissions generated by the community go below zero at $-22.8 \mathrm{kt}$. This happens thanks to the fuelling of the mCHP systems, which are entirely carbon-neutral, and the electricity exports are still substantial as shown in Figure 6.

It has to be noted also that the electricity exports, which are significant across all the proposed scenarios, might be subject to curtailments due to grid congestion, thus ultimately increasing the $\mathrm{CO} 2$ emissions generated by the community under the assumptions made.

Moreover, in Scenario 3 it's assumed that all the fuel needed by the local mCHP systems is provided by carbon-free sources. Given the total heating demand from $\mathrm{mCHP}$ of $110.3 \mathrm{GWh}$, met with a CHP system with a thermal efficiency of $60 \%$, the biomass that is to be supplied would range between 1.6 and 3 times the yearly amount of coal (in weight) that is currently being supplied, depending on the type of biomass that is available in the area [18].

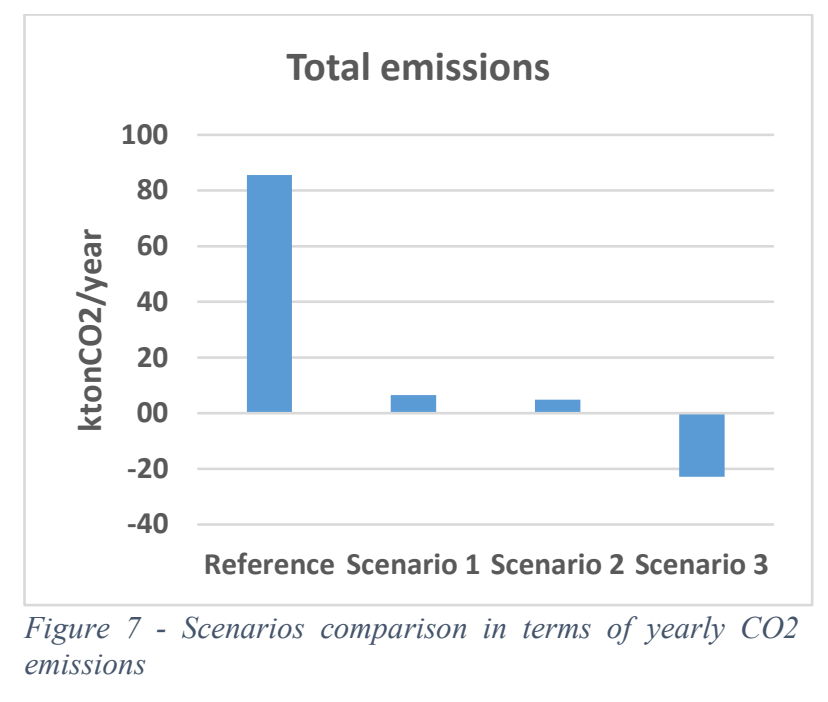

\subsection{Economics \& final remarks}

Finally, a last comment is made on the economics of the proposed configurations.

Considering the data shown in Table 1 and Table 2 a total operational expenditure (OPEX) sustained by the district (considering it as a single entity) would be of approximately 1.5 million USD per year for the supply of coal and electricity.

For the rest of the proposed scenarios, a proper estimation of the OPEX is not as straightforward as they would be heavily dependent on potential support schemes for renewables electricity compensation, which as of today are still defined on a project by project basis in Kazakhstan [19]. From the electricity export magnitudes shown in Figure 6 it can be deduced that the level of such compensation could have a significant impact in determining the total costs of any of the solutions analyzed in the scenarios. Moreover, reliable data on the potential supply cost for biomass could not be obtained by the authors.

With regard to the capital expenditures (CAPEX), there is a significant difference between scenario 1 and 2 with regard to scenario 3 , as the former is much more CAPEX intensive, specifically with regard to the PV capacity installed. In such cases, even considering potential support schemes the investment would probably be prohibitive for any private citizen, potentially requiring 
the development of novel ownership models such as energy communities.

To conclude, from an economic standpoint no clear winner among the proposed designs can be declared yet given the absence of key information, which might be significantly impacted by near-future renewables/decarbonization supporting policies.

\section{Conclusions}

This study investigated potential pathways to switch the energy supply, both for electricity and heating, of a community located in Kazakhstan to $100 \%$ renewable energy. The aim is to achieve a significant curb in $\mathrm{CO} 2$ emissions with respect to the current baseline case that largely uses fossil fuels (coal).

A set of scenarios studying different system configurations using solar energy by means of PV systems and/or biomass is defined and studied by means of the EnergyPLAN model. With regard to meeting the heating demand both heat pumps and household size micro-CHP systems are studied.

The results show that the full electrification of the heating demand and the meeting of all the community's electricity requirements by PV systems installed on-site would both require very large PV installations, most probably exceeding the space availability of the buildings in the district, and most importantly generate significant hour-by-hour electricity imbalances, ultimately leading to the community being more reliant on the electric distribution grid. This only slightly gets better by enhancing the community storage capabilities with thermal energy storage systems at the individual single-household level

On the other hand, limited to a more reasonable size the PV system and switching part of the heat demand to biomass-based micro CHP could better meet the heating requirements of the community, provided that the needed biomass (up to 3 times the mass of the current coal supply) can be supplied to the community.

Future developments of this study could broaden the span of technological options to reach decarbonization targets. As an example, considering community-level wind projects, and most importantly the impact on the heating demand of enhanced energy efficiency measures on the building stock.

\section{References}

[1] The World Bank. Decarbonizing Development. 2015. https://doi.org/10.1596/21889.

[2] Mehigan L, Deane JP, Gallachóir BPÓ, Bertsch V. A review of the role of distributed generation (DG) in future electricity systems. Energy 2018;163:822-36. https://doi.org/10.1016/j.energy.2018.08.022.

[3] Alanne K, Saari A. Distributed energy generation and sustainable development. Renew Sustain Energy Rev 2006;10:539-58. https://doi.org/10.1016/j.rser.2004.11.004.
[4] Lund H. Renewable Energy Systems: A Smart Energy Systems Approach to the Choice and Modeling of $100 \%$ Renewable Solutions. Elsevier Ltd; 2014.

[5] IEA. Kazakhstan Energy Factsheet n.d. https://www.eu4energy.iea.org/Documents/Kaz akhstan-Info-FINAL.pdf.

[6] UNDP. Kazakhstan Renewable Energy Snapshot. 2014.

[7] Karatayev M, Clarke ML. Current energy resources in Kazakhstan and the future potential of renewables: A review. Energy Procedia 2014;59:97-104. https://doi.org/10.1016/j.egypro.2014.10.354.

[8] Bogdanov D, Toktarova A, Breyer C. Transition towards $100 \%$ renewable power and heat supply for energy intensive economies and severe continental climate conditions: Case for Kazakhstan. Appl Energy 2019;253:113606. https://doi.org/10.1016/j.apenergy.2019.11360 6.

[9] Chicco G, Mancarella P. Distributed multigeneration: A comprehensive view. Renew Sustain Energy Rev 2009;13:535-51. https://doi.org/10.1016/j.rser.2007.11.014.

[10] Lund H, Østergaard PA, Connolly D, Mathiesen BV. Smart energy and smart energy systems. Energy 2017;137:556-65. https://doi.org/10.1016/j.energy.2017.05.123.

[11] Andrukonyte K. Review of the Kazakhstan transition to the Green Economy scenario through increasing the share of renewable heat in energy balance - Heat Pump technologies. 2019.

[12] Pfenninger S, Staffell I. Renewable ninja n.d. https://www.renewables.ninja/.

[13] The World Bank. World Bank Databse n.d. https://data.worldbank.org/.

[14] EnergyPLAN n.d. https://www.energyplan.eu/.

[15] Khan I, Jack MW, Stephenson J. Identifying residential daily electricity-use profiles through time-segmented regression analysis. Energy Build 2019;194:232-46. https://doi.org/10.1016/j.enbuild.2019.04.026.

[16] U.S Department of Energy. Commercial Prototype Building Models. n.d.

[17] Wang R, Zhai X. Handbook of energy systems in green buildings. 2018 . https://doi.org/10.1007/978-3-662-49120-1.

[18] EUBIA. European Biomass Industry Association n.d. https://www.eubia.org/cms/wikibiomass/biomass-characteristics-2/.

[19] European Bank for Reconstruction and Development (EBRD). Renewable Energy in Kazakhstan. vol. 7. 2017. 